\title{
Perception towards Development of Employability Skills by Students: A Module Analysis
}

\author{
Sivajothi Paramasivam*1, John Kian Tan², Kanesan Muthusamy ${ }^{3}$ \\ ${ }^{1}$ School of Engineering, KDU University College, Malaysia. \\ ${ }^{2}$ Department of Mechanical \& Construction Engineering, Northumbria University, Newcastle, UK. \\ ${ }^{3}$ School of Professional Development, Vinayaga Missions International University College, Malaysia. \\ ${ }^{1}$ siva@kdu.edu.my
}

\begin{abstract}
For some time, engineering education literature has suggested that the employability capability of engineering graduates does not meet the expectations of many local modern industries. The need to enhance their employability skills is critical because employability has been a challenging national concern and agenda. Thus, gauging student's satisfactory level is a central concern especially in ensuring engineering graduates are able to bridge between their acquired skills and the elementary demands of the labour market. The study entails a review of established research to understand the views and perceptions of engineering undergraduate students in harnessing their employability skills through Barrie's teaching content approach in the Engineering Product Development module. The study described in this paper used 55 responses from engineering students to a standardized student feedback questionnaire over 3 years, to gauge their overall satisfaction with the module as well as to explore perception associated with students' learning experiences, including a two-fold study on collaborative learning experience and satisfactory development of ten important attributes that are closely aligned towards adapting to work environment. The findings indicate that $67.3 \%$ of the students are satisfied with the module in terms of nurturing them with crucial employability skills desirable for the workforce. Besides, the result provides a significant impact of adoption of teaching content mode in the effort of enhancing the teaching and learning process towards producing graduates with broader employability skills.
\end{abstract}

Keyword - engineering education, perception, outcome-based, employability skills, teaching content

\section{INTRODUCTION}

Enhancement of employability skills in higher engineering education have always been a subject of grave concern as critical need of these elements among graduates are essential to fulfil the modern industry's job expectations. In fact, due to competitive nature of engineering activities, industry are also recognizing the centrality of greater need of contemporary professional attributes, understanding, and capabilities of graduates; which has indirectly created a drastic impact on the employability rate of engineering graduates. In this connection, ample evidence indicated existence of a significant gap between many capabilities developed at the university compared to the expectation of modern industry [1-4]

Employability skills are also commonly known as graduate qualities, transferability skills, employability skills or graduate capabilities which emphasize on nurturing of non-technical skill or abilities in nature which are essential for employability at some level [4-7]

As such, the educational curriculum should be frequently revaluated to be relevant and to gravitate towards shaping the graduate's attributes that are desirable to the industry. However, there is a growing concern that the higher engineering education responsible for producing graduates with broader skills and attributes that are beyond technical and discipline competencies is not keeping pace with the need of work front. In this connection, prioritising improvement in the engineering education system towards a different dimension is crucial in influencing the current trends in the engineering education in addressing this shortfall.

Integration of employability skills into the curriculum is currently considered to be the major theme in higher engineering education in an effort to align towards demand of modern industry. Consequently, the drive to embark on this work lies within a two-fold belief; firstly to gauge students' perception towards gaining valuable employability traits especially learning within a collaborative environment. Secondly, to gauge students' perception on the important employability skills that would be of great appeal to industry.

Thus, the drive to nurture work abilities among entry level graduates that meets aspiration of employers has brought the concern of employability skills to the forefront of many higher educational institutions interest. 


\section{Desirable Employability Skills and Teaching Methodologies}

The industry, as an important stakeholder that provides employability to entry level graduate engineers are facing major crisis of securing engineering talents of the right ingredients to drive their mission in finding solutions to global challenges in various sectors. The reason being, engineering practice today requires talent pool of greater knowledge and skills of real world approach which has indirectly created a drastic change towards expectation of industry within the landscape of labour market. It was lamented that the current work demand circumstances experienced by practicing engineers are substantially different of those faced almost a decade ago. In reality, due to constant evolvement of technologies and knowledge and skills requirements, newly recruited engineering graduates are used in a wide range of job roles and carry a high expectation of dominating the workforce to contribute, innovate and spearhead beyond current practice [8].

Whilst engineering education in Malaysia cannot be described as substandard, it is nevertheless has raised concern among industry; according to [5] that these graduates lack an array of desirable employability skills that includes optimizing knowledge for invention, decision making, communication skills, leadership qualities, teamwork abilities, critical thinking and innovative problem-solving skills. This argument was reinforced through work of [9-10] that result of a survey gathered in 2006 indicated that $15.3 \%$ of engineering graduates were unemployed due to lack of preparation of desirable employability or employability skills for a successful career at the local domain.

Consequently, in addition to students' intellectual development, universities also need to focus on identifying gaps on the critical employability skills required by entry-level engineering graduates at workplace. It was indicated that universities across the globe lacking emphasis on nurturing employability skills and abilities in their educational mission, which has resulted continuous critics from industry players which has direct bearing on employability rate of talent pool [11-12, 5].

This argument was further strengthen through a report which outlined an extensive research study that span across selected countries in Asia, in exploring employer's perception of the employability skills of new graduates. In fact, outcome of studies by [13] showed that in reality, engineering students are not well equipped with a string of the desirable employability skills within the Asia region as shown in Figure 1 for a competitive and globally work environment.

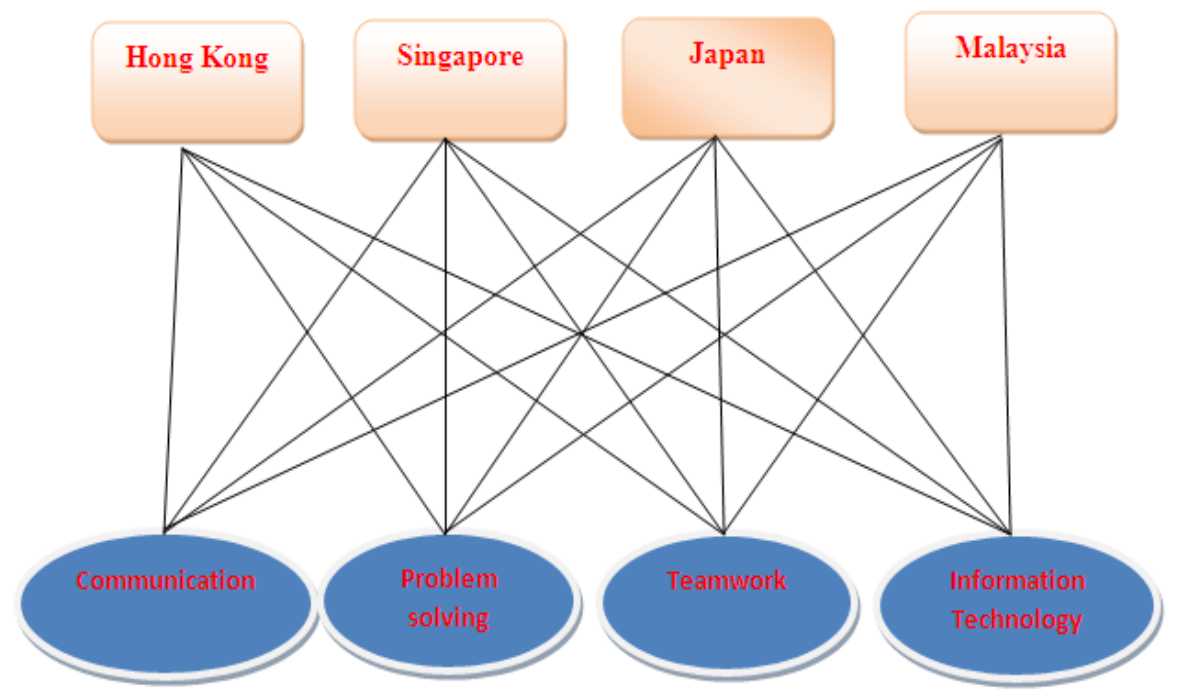

Fig. 1. Essential skills desirable by industry across the many nations [13]

In this relation, the development of employability or employability skills have common focus which is for recognizing an important set of skills that supports the effectiveness of optimizing technical and non-technical traits at workplace. Thus, pose a question if the community of educators and students ignorant on the demand of employability skills which has created an impact on the labour market that has direct bearing on the employability rate of graduates.

Acquisition of employability skills and abilities among others such as communication skills, problem-solving, teamwork abilities and information technology among graduates are on the top priority list of many modern industries. Industry perceive that securing talent pool with such skills would positively enable them to fit into and remain in the work environment. Consequently, reflects that industry require these graduates to have contemporary workplace professional attitudes, understanding and skills. 
In fact, it was lamented that the traditional mode of prescriptive pedagogy which has dominated engineering education since its inception apparently fail to create the desirable impact aspired by employers in terms of attainment of graduate attributes among engineering hires [14]. Consequently, improvement on teaching and learning outcomes needs to be prioritized, as the UNESCO report on graduate employability in Asia strongly indicated that currently, employers are demanding graduates of good work characteristics for the workforce from institutions of higher education within the Asia region [15].

In this relation, engineering educators today are confronted with the issue of how best to ensure that engineering graduates will continue to be relevant and bring value to the job market. This situation is further compounded as worldwide movement towards "outcome-based" climate has posed challenges to engineering educators to provide effective teaching and learning process that emphasize on nurturing the desirable employability or graduate attributes among professional engineering undergraduate learners [16, 2, 17-18].

The cultural shift towards "outcomes based" teaching and learning process in the engineering undergraduate level was the brainchild of concerted and collective effort of accrediting body of Australia, New Zealand, Canada, the US, Ireland and Great Britain; thus giving birth to Washington Accord [19-20].

It was gathered that the Washington Accord is an international accreditation agreement signed in 1989 for education and professional engineering degree programmes. It signifies a mutual recognition of equivalency between each engineering degree programmes accredited by the responsible bodies in each signatory countries. Eventually, this agreement recognises that engineering graduates from these programmes have met the academic standards for entry into the practice of engineering in any signatory country [21, 16-18].

Educational mission and outcomes has often been regarded as an important element of the professional engineering programme that dictates emphasize on the teaching and learning activities. Consequently, being part of the signatory member, this situation has significantly pushed professional engineering education to innovate the teaching and learning activities towards "outcomes base" culture that demands graduates to exhibit graduate attributes that best fits the ever evolving industrial landscape [11, 16, 8, 22]. Thus, the engineering professional body is increasingly called upon to play a key role in ensuring the process of fully integrating new knowledge and more specifically development of graduate skills into the curriculum.

Greater accountability on universities to harness students' employability skills and attributes through the teaching and learning process has brought outcome-based culture to the forefront of higher engineering education policies. Consequently, if these skills are to be incorporated into engineering education in a meaningful way, it will require a significant change in teaching methodologies and technologies, and may hasten the incorporation of what is currently seen as innovative or even radical approaches to education.

In this relation, according to [23], six categories of how to teach employability attributes (capabilities) was proposed by Barrie as shown in Figure 2 and among the approach used was teaching content - attributes are taught within discipline subject as part of the subject. A moderate complexity mechanism that could be easily implemented within the teaching environment that yields positive and satisfactory outcomes.

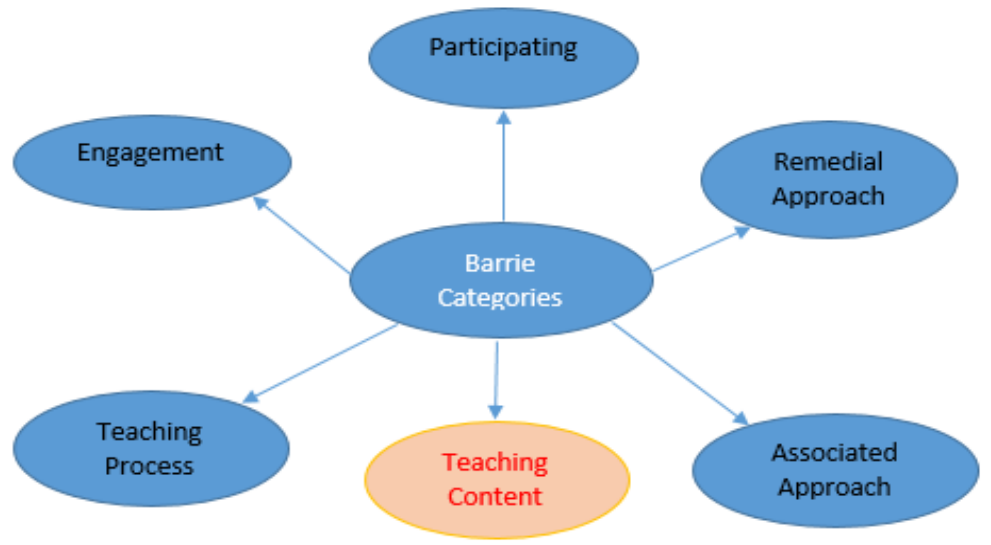

Fig. 2. Teaching Graduate Attributes proposed by Barrie [23]

As an applied discipline, engineering education has a close and strong linkage with its industry in order to educate engineering students by keeping abreast with the current industry trends. In this relation, the author also involved field engineers from industry into the teaching content method. Industry had much to offer to university in terms of a different way of thinking about real world technical issues, innovative solutions and access to new technologies. As such, this module occasionally use industry experts as a learning paradigm in harnessing potential richness of engineering practices into the teaching and learning activities as it was viewed 
beneficial towards enhancing students' learning curve. Consequently, outcome of research work by [24] indicated that greater inclusive representation of industry into the teaching and learning process of the professional engineering programme yield positive significance in stimulating students towards engineering practice with greater learning opportunities beyond classroom settings

\section{III.STUDY STRATEGY AND SETTINGS}

\section{A. Study Settings: Second Year Engineering Module}

The author taught and implemented teaching content method into a second year module of the Electrical and Electronic engineering degree programme of the Northumbria University entitled Engineering Product Development (Module code: EN0213). This module is part of the Bachelor of Engineering (Hons) Electrical and Electronic engineering programme developed by Northumbria University Newcastle (NU) which is offered under a franchise model at KDU College, Petaling Jaya Campus. The programme is offered as a 3+0 arrangement and the curriculum mirrors of that offered in the partner's university with a stringent moderation and quality implementation process. This KDU-Northumbria University (3+0) BEng (Hons) in Electrical and Electronic Engineering programme falls under the purview of Malaysian Qualifications Agency (MQA). As such, this programme falls out of the Washington Accord's accreditation exercise.

The module, a non-examination project driven module offered over 8 months to equip students' with the knowledge and skills necessary to research, design, implement and manage projects associated with the development of modern electronic products. Students work in groups of four or five, forming and managing their own "companies", which respond to a client brief for a viable product of commercial value. Topics in the module include exploring development of modern electrical or electronic product with some element of innovation, research ability, business and market analysis, entrepreneurship, quality and engineering economics as well as project management abilities in the pursuit of designing and developing a prototype of origin or partially origin in nature. It is primarily aim for students to harness and apply fundamental theories and practical abilities from previous learning. Secondly, it provides a vehicle for the development of desirable employability attributes that able to transform graduates to meet the changing needs of employers and the modern industries.

This module was delivered to 61 students of various cohorts from 2011-2013 through a mixture of formal lecture, industry engagement through guest lecture and workshops in the area of entrepreneurship, project management, quality control and product patent rights as well as group discussion where students work within their respective group. These groups are to provide their development of project in stages and the role of each members in supporting this given challenges. Assessment involves justification and feasibility study of intended concept, group presentation, and demonstration of their innovative prototype hardware as well as submission of project reports. One of the key challenge of this module is to aid in harnessing student's collaborative learning experience which includes participation, informed decision making, responsibility, leadership qualities, teamwork abilities, fair-play and ethical values as well as communication skills as these relate to desirable attributes of engineering practice. In general, all the attributes listed were deemed to be relevant and important in terms of employability for this current challenging labour market. Furthermore, it also to help students to become more comfortable with handling projects in an efficient and openness to new and challenging perspectives, essentially exposing engineering economic skills among students.

\section{B. Methodology and Ethical Concern}

A quantitative paradigm was chosen for the study using survey method. In fact, it was reinforced by [25] that quantitative method was favourable in various topics of engineering education in supporting a theory or hypothesis towards addressing a narrowly defined research questions, often supported by data collection by means of survey exercise. Hence, quantitative research methods work with data in numerical form collected from a representative sample and analysed usually through statistical methods. The main ethical issue concerned obtaining informed consent from the head of department of engineering. Access to this particular cohort of students was not an issue as the author was the module tutor. Once ethical clearance was given the questionnaires were administrated and students were informed that the questionnaires were anonymous and results would be dealt with in a confidential manner. The nature of the questions within the questionnaire did not provoke any ethical concerns.

\section{Study Survey}

Data source was important to provide a form of connectivity between content to the proposed method. Thus, survey forms as a suitable instrument to gather data efficiently in order to analyse and draw conclusions about the total target population [26-27]. 
The initial draft of the scale was developed by the primary researcher. However, in order to yield positive respond; one focus group discussion with 12 students was held and a draft of 16 indicators prepared. Consequently, Likert scale forms as a widely used method for measuring challenging attributes in majority of qualitative research study. The instrument used in this study is a five - point Likert - scale questionnaire (1 Very Poor, 2 - Poor, 3 - Fair, 4 - Good, 5 - Excellent).

Overall, the number of questionnaire for Part A comprises questions concerning the demographic features such as intakes, gender, nationality level and satisfaction level of the academic rigour demanded in the module.

Part B was designed to meet the objectives of the study, namely to determine the perception among students using 6 items in view of gaining collaborative learning experience in harnessing their employability skills. Furthermore, 10 items were used to determine what they perceived to be important employability traits in the learning process of the module.

Construct validity was ensured as data was sourced from students registered and has successfully completed this particular module. All the respondents took the module with the first author between the years 2011 and 2013. The purpose of the study was explained to all participating students as this involves data collection from students from this module. This takes place at the end of the semester whereby students were invited in a face to face session to fill in a survey to gauge their view and perception level towards development of graduate capabilities throughout the module and how important they themselves deemed ten most important employability or employability traits. The survey also carried out to ascertain to what extent students' perceived issues around learning experience.

In this content of work, two group of employability aspects were identified collaborative learning (participation, teamwork, responsibility, informed decision making, communication, leadership traits, fair-play and ethics). The other group were identified as attributes more closely aligned towards adapting to work environment in supporting industry in meeting their business needs. The students appeared to recognise the emphasis put in developing employability skills associated in the module. Collated results are presented below.

Descriptive analysis of the data was carried out using the Statistical Packages for the Social Sciences (SPSS). Descriptive analysis basically involves working on the primary data through counting and the use of frequency distribution and simple percentage. Collated results are presented below.

\section{IV.RESUlts ANALYSIS AND INTERPRETATION}

A total of 55 surveys were collected of which 6 were partially and incorrectly completed from as total of 61 students, representing a response rate of $90.1 \%$. In response to a question posed on the satisfactory level of learning experience in the module, overall the result indicated that a total of 40 students viewed their perception as satisfactory which collectively constitute satisfied and very satisfied level of $50.9 \%$ and $21.8 \%$ respectively.

TABLE 1. The demographics of the students in this study in terms of gender and the type of students

\begin{tabular}{|l|l|c|c|}
\hline \multicolumn{1}{|c|}{ Item } & & Number & Percentage (\%) \\
\hline \multirow{2}{*}{ Gender } & Male & 49 & 89.1 \\
\cline { 2 - 4 } & Female & 6 & 10.9 \\
\hline \multirow{2}{*}{ Type of Students } & Local & 25 & 45.4 \\
\cline { 2 - 4 } & International & 30 & 54.6 \\
\hline
\end{tabular}

The demand and expectation of students to exhibit broader array of skills beyond knowledge in this module forms as a challenging feat. As such, outcome of this question posed as illustrated in Figure 3, indicates that students rated positively on their overall satisfaction with demands of this subject with $47.3 \%$ and $20.0 \%$ for satisfied and very satisfied respectively. Conversely, remaining 33.7\% of the students' possibility lacked general motivation towards either type of assessment activity or the collaborative learning settings. In the present study, SPSS was used to determine Cronbach's alpha values for the 16 items based on primary data. This was done to ensure reliability of the data collected. The reliability coefficients of Cronbach's alpha indicated 0.887 and 0.899 for collaborative learning experience and students' perception of satisfaction respectively as shown in Table 2. Both of these values were above the cut-off 0.7 as suggested by [28]. Therefore, items were consider reliable and error-free. The rationale behind content validity is that to examine the extent to which a measuring instrument provides adequate coverage of the topic under study. Table 3 shows the item statistics for collaborative learning experience involving a sample size of 55 students. 


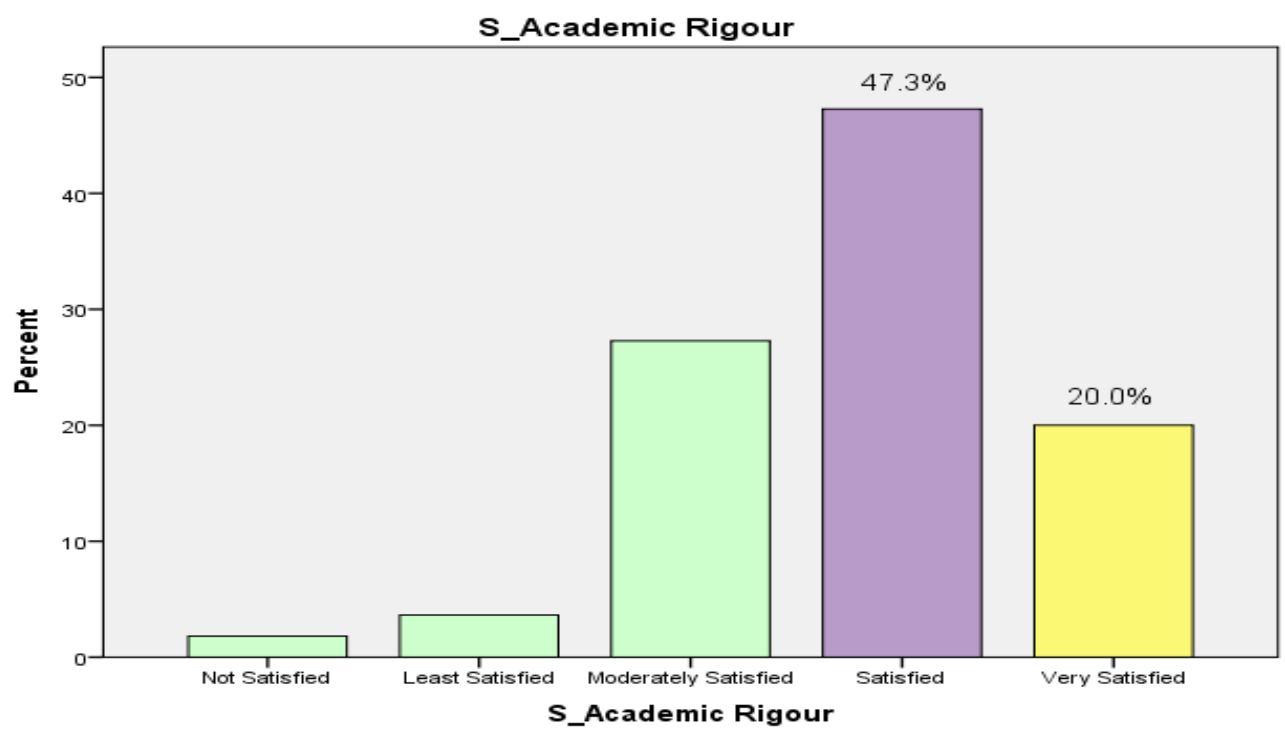

Fig. 3. Satisfaction of the academic rigour demanded in the module

TABLE 2. Reliability measures for the study

\begin{tabular}{|l|l|c|c|}
\hline No. & & No of Items & Cronbach's Alpha \\
\hline 1 & Collaborative Learning Experience & 6 & 0.887 \\
\hline 2 & Students' Perception of Satisfaction & 10 & 0.899 \\
\hline & Overall reliability of the study & 16 & $\mathbf{0 . 8 9 3}$ \\
\hline
\end{tabular}

TABLE 3. Item Statistics for collaborative learning experience

\begin{tabular}{|l|c|c|}
\hline \multicolumn{1}{|c|}{ Employability Skills } & Mean & Standard Deviation \\
\hline Collaborative Work & 3.84 & 0.739 \\
\hline Responsibility & 4.00 & 0.793 \\
\hline Informed Decision Making & 4.02 & 0.782 \\
\hline Communication Skills & 4.05 & 0.780 \\
\hline Leadership Skills & 3.89 & 0.712 \\
\hline Ethical Values & 3.95 & 0.756 \\
\hline
\end{tabular}

Table 4 reflects the outcome to the response on students' perception towards gaining valuable employability traits especially learning within a collaborative environment. As illustrated in Table 4, it is interesting to note that communication skills were ranked as the most preference by students with a total of $80 \%$. The reason being, this learner-centred approach requires students to be actively engaged among peers in a constructive manner especially in putting their ideas, concept, and argument in adoption as well as expressing judgments in the project. Students for this module also indicated that decision making (78.2\%), responsibility (76.4\%), ethical values (76.3\%), leadership traits $(72.3 \%)$ and active participation $(70.9 \%)$ respectively were their choice of preference in view of gaining collaborative learning experience in harnessing their employability skills.

TABLE 4. Rating of Collaborative Learning Experience

\begin{tabular}{|l|c|c|c|c|c|}
\hline Component of Employability Skills & Very poor & Poor & Fair & Good & Excellent \\
\hline Active Participation & $0 \%$ & $3.6 \%$ & $25.5 \%$ & $54.5 \%$ & $16.4 \%$ \\
\hline Responsibility & $0 \%$ & $3.6 \%$ & $20.0 \%$ & $49.1 \%$ & $27.3 \%$ \\
\hline Informed Discussion Making & $0 \%$ & $3.6 \%$ & $18.2 \%$ & $50.9 \%$ & $27,3 \%$ \\
\hline Communication Skills & $0 \%$ & $3.6 \%$ & $16.4 \%$ & $50.9 \%$ & $29.1 \%$ \\
\hline Leadership Traits & $0 \%$ & $1.8 \%$ & $25.5 \%$ & $54.5 \%$ & $18.2 \%$ \\
\hline Fair-play \& Ethical value & $0 \%$ & $3.5 \%$ & $20.0 \%$ & $54.5 \%$ & $21.8 \%$ \\
\hline
\end{tabular}

Table 5 below shows the item statistics for students' perception of satisfaction on employability skills involving a sample size of 55 students. 
TABLE 5. Students' perception of satisfaction on employability skills

\begin{tabular}{|l|c|c|}
\hline Employability Skills & Mean & Standard Deviation \\
\hline Communication Skills & 3.89 & 0.854 \\
\hline Leadership Skills & 3.96 & 0.902 \\
\hline Market Sense & 3.96 & 0.816 \\
\hline Critical Thinking & 3.76 & 0.942 \\
\hline Ethical Values & 4.04 & 0.860 \\
\hline Entrepreneurial Skills & 3.87 & 0.862 \\
\hline Optimization of Modern Tools & 3.84 & 0.938 \\
\hline Responsibility & 3.96 & 0.881 \\
\hline Dependability & 3.87 & 0.982 \\
\hline Collaborative Learning & 3.96 & 0.881 \\
\hline
\end{tabular}

The small scale study described in this paper bore a close relationship between what students perceived was covered well within the module and what they perceived to be important employability traits. Given the name and nature of the module, "ethical value" ranked highly in terms of its perceived satisfactory development through the module, as did "leadership", "teamwork", "responsibility", "market strategic", "coping and dependability”, “critical thinking”, “entrepreneurial”, followed by "modern tool optimization” and "communication" which is illustrated in Table 6. On the basis of these responses, it appears that the key aim within the module of helping students achieve greater understanding of the importance of employability skills that are highly desirable by employers at least had the potential to be met. On the other hand, skills such as "problem-solving”, "management skills" and "engineering economics” were rated rather low as probably this module in essentially their first contact with and formal introduction to the world of engineering in the business context.

TABLE 6. Students perception of satisfaction through the module

\begin{tabular}{|l|c|}
\hline Employability Skills & Percentage \\
\hline Ethical Values & $34.5 \%$ \\
\hline Leadership Skills & $32.7 \%$ \\
\hline Teamwork Skills & $31.0 \%$ \\
\hline Responsibility Skills & $30.9 \%$ \\
\hline Market Strategic Skills & $29.1 \%$ \\
\hline Coping and Dependability & $29.0 \%$ \\
\hline Critical Thinking Skills & $27.3 \%$ \\
\hline Entrepreneurial Skills & $27.1 \%$ \\
\hline Technology Skills & $27.0 \%$ \\
\hline Communication Skills & $25.5 \%$ \\
\hline
\end{tabular}

\section{CONCLUSION}

Due to a growing emphasis on employability skills, adoption of appropriate teaching-learning approaches is positively explored in engineering curriculum. In fact, the engineering education sector has been increasingly modernized to encourage lecturers to deploy collaborative learning activities to engage students meaningfully with the concept of employability skills development. The outcome of the results which is limited to students' perception indicates that they are satisfied with the manner the module was conducted and acknowledge that it sustains strong academic demand towards attainment of desirable employability skills.

Despite being excluded from the WA criteria due to its 3 years duration of study stigma, this module sustains its focus towards nurturing of critical employability skills that are desired by many modern industry. Thus, this study is important to bridge student engagement with development of employability skills and student understanding of their importance and relevance at workplace; therefore, provides a good platform for educational practitioners to reinforce students' limited knowledge and understanding on the realities of engineering practice and work demand during their course of study. In addition, the outcome of study provide a platform to ascertain whether the perceptions of students in terms of development of employability skills was similar to that of the course tutor (author). 
Finally, due to a positive indication of adoption of teaching content approach for this module; enforces educational navigators to become attuned towards more participatory and self-regulatory teaching, learning and assessment in shaping critical employability skills of engineering graduates that appeals modern industry. A second year module which aims to harness and nurture crucial employability skills is cited, where students appear to recognize value in this approach.

\section{ACKNOWLEDGMENT}

The authors acknowledge the support by the KDU University College, Malaysia and Northumbria University, Newcastle, UK.

\section{REFERENCES}

[1] S. A. Male, M. B. Bush and E. S. Chapman, Identification of competencies required by engineers graduating in Australia, Proceedings of 20th Australasian Association for Engineering Education Conference, December, 2009, pp. 882-887.

[2] M. Y. Yuzainee, A. Zaharim and M. Z. Omar, Employability skills for an entry-level engineer as seen by Malaysian employers, IEEE Global Engineering Education Conference (EDUCON) -Learning Environments and Ecosystems in Engineering Education, Jordan, April 2011, pp. 80-85.

[3] F. Kamel, M. Baguley and D. Thorpe, Enhanced graduate attributes by engaging engineering students in teaching episodes, Proceedings of the 2011 Australasian Association for Engineering Education (AAEE) Conference, Fremantle, Western Australia, 2011, pp. 421- 426.

[4] M. Shah and C.S. Nair, Employer satisfaction of university graduates: Key capabilities in early career graduates, Teaching and Learning Forum, 2011, pp. 1-10.

[5] A. Zaharim, Y.M. Yusoff, A. Mohamed, M.Z. Omar, N. Muhamad and R. Mustapha, Practical framework of employability skills for engineering graduates in Malaysia, IEEE EDUCON Education Engineering 2010 The Future of Global Learning Engineering Education, Madrid, Spain, April. 2010, pp. 921-927.

[6] L.N. Wood, T. Thomas and B. Rigby, Assessment and standards for graduate outcomes, Asian Social Science, 7(4), April 2011, pp. $12-17$.

[7] E. P. Byrne, Enhancing engineering employability in the 21st century; handling uncertainty and complexity through 'new entrepreneurship, 4th International Symposium for Engineering Education, ISEE 2012, Educating the Engineers of Tomorrow, England, July 2012, pp. 1-9.

[8] A. Zaharim, Y.M. Yusoff, M.Z. Omar, A. Mohamed and N. Muhamad, The comparison of priority engineering employability skills, International Journal of Engineering and Technology, 7(2), 2010b, pp. 61-74.

[9] S. Z. Norshima, Are graduates to be blamed? Unemployment of computer science graduates in Malaysia, 2008, pp. 1-16.

[10] M. S. M. Saad, A. Robani, Z. Jano and I. A. Majid, Employers' perception on engineering, information and communication technology (ICT) students’ employability skills, Global Journal of Engineering Education, 15(1), 2013, pp.42-47.

[11] S. Barrie, Rethinking employability graduate attributes, 27(1), April 2005, pp.1-5.

[12] A. Patil, C.S. Nair and G. Codner, Global accreditation for the global engineering attributes: A way forward, Proceedings of the 2008 Australasian Association for Engineering Education (AAEE) Conference, 2008, pp. 1-8.

[13] Zaharim, Y.M. Yusoff, M. Z. Omar, A. Mohamed, N. Muhamad and R. Mustapha, Perceptions and expectation towards engineering graduates by employers: A Malaysian case study, WSEAS Transactions on Advances in Engineering Education, 6(9), September 2009, pp. 296-305.

[14] R.M. Felder, B. McCabe, M. Pantazzidou and D. Philips, Engineering education: A tale of two paradigms, Shaking the Foundation of Geo- Engineering Education, Leiden, CRC Press, 2012, pp. 9-14.

[15] UNESCO, Graduate employability in Asia, Bangkok, 2012, pp.1-96.

[16] M. N. M. J. Megat, Accreditation and quality of engineering education: The Malaysian Experience, International Journal of Engineering and Technology, 5(2), 2010, pp. 39-46.

[17] L. V. Acker and J. Bailey, Embedding graduate skills in capstone courses, Asian Social Science, 7(4), April, 2011, pp. 69-76.

[18] N. Rajaee, M. H. Husin, M. F.M. Sabri, D. N. S. D. A Salleh and N. L. Yew, Towards accreditation in engineering education: A review of learning tools, pedagogies and assessment procedures in Department of Electronic Engineering, UNIMAS. 2013.

[19] F. F. Chang, D. C. Wang and C. Y. Chang, Internationalization of engineering education in Taiwan: Accreditation approach based on Washington Accord signatories’ accreditation system, Educational Policy Forum, 11(2), 2008, pp.1-36.

[20] A. Patil and G. Codner, Accreditation of engineering education: review, observations and proposal for global accreditation, European Journal for Engineering Education, 32(6), 2007, pp. 639-651.

[21] J. A. Memon, R.E. Demirdogen and B.S. Chowdhry, Achievements, outcomes and proposal for global accreditation of engineering education in developing countries. World Conference on educational sciences, 2009, pp. 2557- 2561.

[22] M. T. Oladiran, G. Pezzota, J. Uziak and M. Gizejowski, Re-engineering an engineering education programme: Example of the University of Botswana, Proceedings of the 2012 Australasian Association for Engineering Education (AAEE) Conference, Melbourne, Australia, 2012, pp.1-9.

[23] B. Shen, G. Buskes, J. Evans and A. Ooi, Diversity and longevity: A framework for graduate attribute development in engineering education, Proceedings of the 2011 Australasian Association for Engineering Education (AAEE) Conference, Fremantle, Western Australia, 2011, pp. 382- 388.

[24] S. Paramasivam, J. K. Tan, and K. Muthusamy, Investigating University-Industry Partnership of Higher Engineering Education Using Cause-Effect Analysis and Multi-Criteria Decision Making: A Malaysian Perspective, International Journal of Applied Engineering Research, 10(5), 2015, pp. 3979-3982.

[25] M. Borrego, E. P. Douglas and C. T. Amelink, Quantitative, Qualitative, and Mixed Research Methods in Engineering Education, Journal of Engineering Education, January 2009, pp. 53- 66.

[26] D. K. Bird, The use of questionnaires for acquiring information on public perception of natural hazards and risk mitigation - a review of current knowledge and practice, Natural. Hazards Earth System Sciences, 9, 2009, pp.1307-1325.

[27] D. J. Leiner, Convenience Samples from Online Respondent Pools: A case study of the SoSci Panel, Journal of Communication, 62, 2012, pp. 1-36.

[28] J. C. Nunnally and I.H. Bernstein, Psychometric Theory $3^{\text {rd }}$ edn, McGraw-Hill, New York, 1994. 


\section{AUTHOR PROFILE}

Sivajothi Paramasivam holds a M.Eng. in Manufacturing Management from the University of South Australia and a Bachelor's Degree (with First Class Hons) in Electrical and Electronic Engineering from the University of Lincolnshire and Humberside, UK. He has roughly 18 years of work experience in the higher education sector and currently holds the position of the academic head/senior staff of the School of Engineering in KDU University College, Utropolis, Glenmarie. His work experiences include roles such as the Programme Coordinator, Industrial Training Liaison Officer and Academic Department Head for the School of Engineering. His areas of interest covers Telecommunication, Energy Efficiency and Management, Total Quality Management and Engineering Education. He was formerly part of Telekom Malaysia Berhad and was part of a panel of experts for program standards for Engineering and Engineering Technology initiatives of Malaysian Qualifications Agency (MQA). He is a Chartered Engineer with the Engineering Council, United Kingdom (CEng). He is also a Member of the Institution of Engineering and Technology (IET), UK.

John Kian Tan studied Naval Architecture in the UK before returning to Singapore to enroll on a Mechanical Engineering course. He came to Northumbria in 2001 after lecturing at Newcastle University and currently subject leader for the Mechanical Engineering area. He derive pleasure from being able to help students build confidence and achieve their full potential both in their academic and professional careers. Research adds an additional learning and enriching element to this job, as one continues to explore new areas and applies these in various ways: linking to teaching, updating the curriculum, or tackling industrial problems. Drawing satisfaction from helping students, stimulating own interests with research the results of which either feedback to teaching or feed forward to industry. Among the area of research are in discipline-based and pedagogic research. Data analysis, safety/risk analysis, multiple criteria decision making and engineering design are some of his disciplined-based research interests. Pedagogic research interests include linking research to teaching, helping students achieving learning outcomes required to achieve professional qualification and assessment of learning outcomes.

Kanesan Muthusamy received his $\mathrm{PhD}$ degree in Information Engineering from the Graduate School of Engineering, Osaka University, Japan, in March 2002. He was the recipient of the Monbusho Scholarship from the Government of Japan. The other academic qualifications include M.Eng. from the University of Malaya in 1997 and B.Eng (Hons) in Mechanical Engineering from the University of Technology Malaysia in 1989. Currently, he is a senior academic staff of the School of Professional Development at Vinayaka Missions International University College (VMIUC) and was trained by Motorola University as a Six Sigma Black Belt consultant. On providing solution on this aspect, he was appointed as consultant by numerous organizations including, Motorola, Panasonic, OUM, Nestle, AEON/Jusco, Gamuda, Brunei Telecom, MBAM, Felda, Sime Darby, CCM and Westport. Currently, he is a Professional Engineer registered with the Board of Engineers, Malaysia, Panel Member for Malaysian Qualifications Agency (MQA) and Engineering Accreditation Council (EAC). The training expertise undertaken includes Operations Management (OM), Total Productive Maintenance (TPM), Project Management (PM), Green Technology \& Environmental Management, Total Quality Management (TQM), Six Sigma, Design of Experiment (DOE), Benchmarking, Lean Management and many more. 